\title{
Geopolymerization of Coal Fly Ash, Ceramic Tile Waste and Spent Bleaching Earth for the Production of Sodium Aluminosilicate Monolith
}

\author{
Renzo MACASIL ${ }^{1}$, Anne Paulinne Redublo ${ }^{1}$, Amabelle SANTOS $^{1}$, Clark Ivan TORRES ${ }^{1}$, and Denvert PANGAYAO ${ }^{1, *}$ \\ ${ }^{1}$ Chemical Engineering Department, College of Engineering and Technology, Pamantasan ng Lungsod ng Maynila, \\ Intramuros, Manila, Philippines
}

\begin{abstract}
In this study, compressive strength, density, porosity, and methylene blue adsorptive intensity of sodium aluminosilicate monolith produced from coal fly ash (CFA), ceramic tile waste (CTW), and spent bleaching earth (SBE) were evaluated. Using simple lattice mixture design, CFA-CTW-SBE blend with mass ratio of $55.95 \%$ CFA, $38.73 \% \mathrm{CTW}$, and $5.31 \% \mathrm{SBE}$, and an alkali solution containing $80 \% 8 \mathrm{M} \mathrm{NaOH}$ and $20 \%$ sodium silicate, resulted to a maximum desirability of $12.4 \mathrm{MPa}$ compressive strength, $1310 \mathrm{~kg} / \mathrm{m}^{3}$ density, $17.03 \%$ porosity, and $1.63 \%$ methylene blue adsorption intensity. The properties of the product conform to the specifications of ASTM C90-14 for lightweight load-bearing concrete.
\end{abstract}

\section{Introduction}

Geopolymerization is an innovative technology that can utilize raw materials rich in alumina and silica to produce new materials characterized by threedimensional polymeric structures called geopolymers. Sodium aluminosilicate monolith is a geopolymer that can be used as concrete in building and construction materials (Provis and van Deventer, 2014; Malenab et al., 2017). Moreover, it has the greatest potential to replace zeolite adsorbent in removing heavy metal from wastewater since they have similar amorphous structure constituted by $\mathrm{SiO}_{4}$ and $\mathrm{AlO}_{4}$ tetrahedra (Novais et al., 2018; Arrifin et al., 2017; Lee et al., 1997). Furthermore, this can be applied in high temperature applications such as furnace linings, fire resistant coatings, thermal insulation and wall panels (Provis and Bernal, 2014).

In the production of sodium aluminosilicate monolith, materials rich in alumina and silica are reacted and formed by alkaline activation at slightly higher than room temperature (Nguyen et al., 2017; Sanjayan et al., 2015; Sumabat et al., 2015). Industrial by-products such as coal fly ash (CFA), ceramic tile wastes (CTW), and spent bleaching earth (SBE) shows great potential for silica and alumina sources (Tigue et al., 2018; Oladosu et al., 2017; Aly et al., 2018).

CFA is an industrial by-product derived from coal combustion in thermal power plants. According to Depatment of Energy (DOE, 2018a), coal-fired power plants has remained the dominant energy source in the Philippines with a share of $35.4 \%$ or 8,049 megawatts (MW), and it will continue to increase to over $55 \%$ by 2027. In addition, the total generation of CFA amounted to $168,650.20$ metric tons for year 2017 (DOE, 2018b). This by-product has been minimally utilized as an additive in cement (Sumabat et al., 2015) and largely being disposed in the landfills near the power plant. In addition to the issue of increasing need for landfill area, coal ash disposal poses the threat of the contamination of surface waters and groundwater from its heavy metal and mineral contents and poses harmful effects on the residents living near the power plant (Kalaw et al., 2018; Ho and Orbecido, 2018).

Another raw material used is SBE which is a solid waste generated in vegetable oil industry. During the refining process, bleaching earth is used to remove color, phospholipids, residue gums, oxidized products and any trace metals from the oil. These colored pigments are trapped and absorbed in the bleaching earth, thus transforming the originally whitish earth to dark grey, which is the generated SBE. The amount of SBE generated is 0.5 to $1 \%$ of the total production of vegetable oil. (Huang and Chang, 2010). In the Philippines, 1,781,000 tons of vegetable oil is produced in 2017, generating 13,357.50 tons of SBE at an average (Organisation for Economic Co-operation and Development and Food and Agriculture Organization, 2017). It is considered an industrial by-product as there is hardly any practical application for it (Oladosu et al., 2017). Moreover, SBE is highly susceptible to spontaneous combustion due to the $20 \%$ to $40 \%$ by weight of oil entrained in it. SBE is usually disposed in landfills or waste dumps which can cause environmental hazards, since it is prone to catching fire, besides polluting the ground water (Wangrakdiskul et al., 2015). Handling and disposing of SBE is a fire risk, an operating expense, and a source of environmental

* Corresponding author: dcpangayao@plm.edu.ph 
regulatory concerns (Oladosu et al., 2017; Huang and Chang, 2010).

The third raw material is CTW which is a solid waste generated from ceramic industry, which was used because of its high generation and good alumina and silica content. According to Reig et al. (2013), CTW is a non-hazardous material, but its non-biodegradability poses a problem because only $65 \%$ of this waste is recycled leaving a large amount of solid waste from the ceramic tile industry.

In this study, the proponents aimed to produce sodium aluminosilicate monolith from the ternary mixture of CFA, CTW, and SBE that conforms to the properties of lightweight concrete panels. The raw materials were characterized using X-ray fluorescence (XRF) spectroscopy. In addition, geopolymerization is highly dependent on the reactivity of the materials used. To determine the reactivity of the raw materials, dissolution tests were conducted at room temperature adapting the procedure outlined in the study of Kalaw et al. (2018). A simple lattice mixture design generated from Design Expert 11 software was used to determine the mix proportions and to obtain the optimum mix conditions of a CFA-CTW-SBE ternary mix geopolymer to obtain the properties for lightweight and medium strength structural material. The mechanical properties of the geopolymer samples formed were evaluated using compressive strength tests. Lastly, to assess its suitability as adsorbents for wastewater treatment, the optimum ternary mix geopolymer obtained were used for adsorption of methylene blue and its mechanism were fitted using Langmuir and Freundlich isotherm models.

\section{Materials and Methodology}

\subsection{Sources of raw materials}

CFA was obtained from a coal fired power plant located in Batangas, Philippines and was used as received. On the other hand, SBE samples were obtained from a palm oil manufacturing facility in coordination with Department of Environment and Natural Resources (DENR). Lastly, CTW was obtained from a ceramic tile manufacturing plant in Batangas, Philippines. Alkali activator used in the study was prepared using analytical reagents purchased from a local company at an 80-20 mass ratio of $8 \mathrm{M} \mathrm{NaOH}$ (sodium hydroxide) solution and $\mathrm{Na}_{2} \mathrm{SiO}_{3}$ (sodium silicate) solution. In addition, the blowing agent used is $3 \%$ hydrogen peroxide solution.

\subsection{Characterization of raw materials}

X-ray Fluorescence analysis was conducted to determine the elemental composition of raw materials. For CFA, the analysis was provided by the power plant company in Batangas. On the other hand, the other raw materials were tested at InterTek Minerals Testing Philippines.

\subsection{Dissolution tests}

To determine the reactivity of the raw materials, dissolution experiments were conducted at room temperature. First, dissolve $2.5 \mathrm{~g}$ of the sample (CFA, CTW, SBE) in three separate beakers containing $50 \mathrm{~mL}$ of $80 \% 8 \mathrm{M} \mathrm{NaOH}$ solution and $20 \%$ sodium silicate. Next, stir the solution continuously for two hours and filter the solid residues. Then, dry the filtered solid residues at $105^{\circ} \mathrm{C}$ until the weight is constant. Finally, calculate the percent dissolution using the formula:

$\%$ dissolved $=\frac{\text { mass of sample }(\mathrm{g})-\text { solid residue }(\mathrm{g})}{\text { mass of sample }(\mathrm{g})} * 100$

\subsection{Pre-Treatment of raw materials and geopolymer production}

\subsubsection{Preparation of raw materials}

The average particle size of CFA and SBE used is 425 $\mu \mathrm{m}$ (mesh 40). On the other hand, CTW was ground for 30 minutes and sieved using Tyler Mesh $40(425 \mu \mathrm{m})$. Also, residual oil in SBE was removed using isopropanol with $1: 1.5(\mathrm{w} / \mathrm{w})$ ratio through leaching at $70^{\circ} \mathrm{C}$ for 60 minutes, then the resulting mixture was filtered and the recovered SBE cake was dried at $90^{\circ} \mathrm{C}$ for 1 hour.

\subsubsection{Geopolymer production}

CFA, ground CTW, and pretreated SBE were mixed according to different mix ratios obtained using simple lattice design for mixtures from Design Expert 11 as shown in Figure 1 and Table 1 and reacted with alkali solution at 70-30 mass ratio at ambient temperature for 30 minutes to facilitate breakdown of aluminosilicates releasing reactive silicate and aluminate monomers, which then reforms and rearranges to a $3 \mathrm{D}$ structure geopolymer. Afterwards, 3\%(w/v) hydrogen peroxide is reacted with the geopolymer slurry at ambient temperature for 30 minutes, then the mixture is poured in $50 \mathrm{~mm}$ cubical mold and is cured at $50^{\circ} \mathrm{C}$ for 2 hours. Afterwards, the monolith is allowed to cure again for 7 days at ambient room temperature. The compressive strength of the samples were tested using UTM Digimax $\mathrm{C} 0019 / \mathrm{Y}$.

Table 1. Mix Ratios of CFA, CTW, and SBE

\begin{tabular}{|c|c|c|c|}
\hline $\begin{array}{c}\text { Mix } \\
\text { Ratio }\end{array}$ & $\begin{array}{c}\text { CFA (A) } \\
\text { (g) }\end{array}$ & $\begin{array}{c}\text { CTW (B) } \\
(\mathbf{g})\end{array}$ & $\begin{array}{c}\text { SBE (C) } \\
(\mathbf{g})\end{array}$ \\
\hline R1 & 500 & 0 & 0 \\
\hline R2 & 0 & 500 & 0 \\
\hline R3 & 0 & 0 & 500 \\
\hline R4 & 250 & 250 & 0 \\
\hline R5 & 250 & 0 & 250 \\
\hline R6 & 0 & 250 & 250 \\
\hline R7 & 333.33 & 83.33 & 83.33 \\
\hline R8 & 83.33 & 333.33 & 83.33 \\
\hline R9 & 83.33 & 83.33 & 333.33 \\
\hline R10 & 166.67 & 166.67 & 166.67 \\
\hline
\end{tabular}




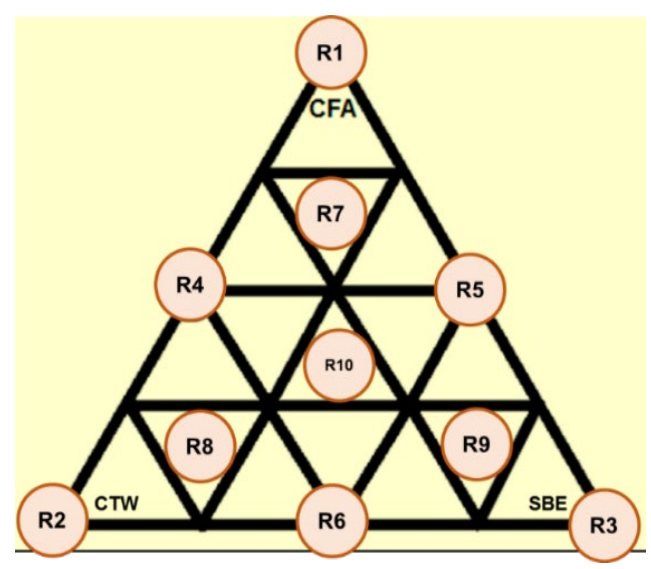

Figure 1. Different Mix Ratios of CFA, CTW, and SBE

In determining the optimal mix ratio of the ternary blend CFA, CTW, and SBE, multiple response surface optimization via desirability functions was used, having compressive strength and density as the output response.

\subsection{Methylene blue (MB) adsorption determination}

For adsorption, the monoliths were immersed in $200 \mathrm{~mL}$ of a solution containing 10ppm MB concentration and stirred occasionally during a predetermined period of time $(30 \mathrm{~h})$ at room temperature. Aliquots from the solution were taken from the liquid, and its $\mathrm{MB}$ concentration was evaluated by determining the absorbance in a UV-vis spectrometer (PerkinElmer $\lambda$ 365) $(664 \mathrm{~nm})$. To determine the adsorption mechanism, the data were fitted using both the Langmuir and Freundlich models.

\subsubsection{Langmuir model}

The Langmuir model assumes homogeneous binding sites and equivalent sorption energies in the surface, and that there is no interaction between the sorbed species (Kim et al, 2015). It is described by the equation:

$$
q_{e}=\frac{C \mathrm{o}-C \mathrm{e}}{m} \times V
$$

Where $q_{\mathrm{e}}$ is the quantity of MB uptake by the monolith $(\mathrm{mg} / \mathrm{g}), C \mathrm{o}$ is the initial concentration of $\mathrm{MB}(\mathrm{mg} / \mathrm{L}), C_{\mathrm{e}}$ is the remaining equilibrium $\mathrm{MB}$ concentration $(\mathrm{mg} / \mathrm{L})$, $V$ is the volume (L) and $m$ is the mass of the monolith (g).

\subsubsection{Freundlich model}

The Freundlich isotherm model, on the other hand, has been interpreted as sorption onto a heterogeneous surface, having sites with different affinity. In that model, one presumes that the stronger binding sites are occupied first, and that the binding strength decreases with the increasing degree of occupation (Kim et al., 2015). The model has the form:

$$
q_{\mathrm{e}}=K_{\mathrm{F}} C_{\mathrm{e}}^{\frac{1}{n}}
$$

where $K_{\mathrm{F}}$ is the Freundlich constant, and $n$ is a parameter which represents the absence of linearity of the adsorbed quantity in function of $C_{\mathrm{e}}$. If the value of $1 / n$ is between 1 and 10, then there is favourable adsorption. Larger values of $n$ suggests, on the contrary, a stronger interaction between the surface of the adsorbent and adsorbate; when $1 / n$ is equal to 1 , this means a linear adsorption, leading to identical adsorption energies for all the sites (Febrianto et al., 2009).

\section{Results and Discussion}

\subsection{Characterization of raw materials}

The elemental composition of the raw materials are shown in Table 2. CFA is classified as Class F fly ash under ASTM C618-05 since the sum of the silica, alumina, and iron oxide is $72.82 \%$, which is greater than $70 \%$. Also, the $\mathrm{Si}: \mathrm{Al}$ ratio of CFA is $2.42: 1$, which is a suitable material for geopolymer products applied in low carbon-dioxide-emission cements and concretes, and toxic waste encapsulation or adsorption. On the other hand, CTW and SBE have Si:Al ratio of 3.79:1 and $6.17: 1$, respectively, which means it can be used as adhesives in various industries operating at 200 to $600^{\circ} \mathrm{C}$ (Dimas et al, 2009; Timakul et al, 2015)

Table 2. Chemical Composition of Raw Materials (\% wt.)
\begin{tabular}{|c|c|c|c|}
\hline COMPOSITION & CFA & CTW & SBE \\
\hline $\mathrm{SiO}_{2}$ & 47.5 & 67.78 & 60.50 \\
\hline $\mathrm{Al}_{2} \mathrm{O}_{3}$ & 19.6 & 17.87 & 9.80 \\
\hline $\mathrm{CaO}$ & 12.3 & 1.21 & 4.15 \\
\hline $\mathrm{Fe}_{2} \mathrm{O}_{3}$ & 5.72 & 5.52 & 8.79 \\
\hline $\mathrm{K}_{2} \mathrm{O}$ & - & 3.00 & 1.02 \\
\hline $\mathrm{MgO}$ & 4.70 & 0.95 & 4.59 \\
\hline $\mathrm{Na}_{2} \mathrm{O}$ & - & 1.96 & - \\
\hline $\mathrm{TiO}_{2}$ & - & 0.63 & 0.96 \\
\hline $\mathrm{SO}_{3}$ & 3.20 & 0.060 & - \\
\hline $\mathrm{P}_{2} \mathrm{O}_{5}$ & - & 0.095 & 5.18 \\
\hline $\mathrm{BaO}$ & - & 0.11 & - \\
\hline Moisture Content & 0.30 & - & 1.94 \\
\hline
\end{tabular}

\subsection{Dissolution test}

Geopolymerization is highly dependent on the reactivity of the materials used. Table 3 shows that CFA has the highest dissolution rate of $46 \%$ among the three raw materials, followed by SBE at $41.60 \%$, then CTW at $27.60 \%$. CFA and SBE are reactive due to their amorphous properties, while CTW has the lowest reactivity because of its crystal structure (Mas et al., 2015) 
Table 3. Dissolution Tests on Raw Materials

\begin{tabular}{|c|c|c|c|}
\hline $\begin{array}{c}\text { Raw } \\
\text { Material }\end{array}$ & $\begin{array}{c}\text { Initial } \\
\text { Mass, g }\end{array}$ & $\begin{array}{c}\text { Solid } \\
\text { Residue, g }\end{array}$ & $\begin{array}{c}\% \\
\text { Dissolved }\end{array}$ \\
\hline CFA & 2.5 & 1.35 & 46.00 \\
\hline CTW & 2.5 & 1.81 & 27.60 \\
\hline SBE & 2.5 & 1.46 & 41.60 \\
\hline
\end{tabular}

\subsection{Optimum ternary mixture ratio}

Table 4 shows the compressive strength and density of sodium aluminosilicate monoliths produced from the mix design of the raw materials.

Table 4. Optimum Ternary Mix Ratio Determination

\begin{tabular}{|c|c|c|c|}
\hline $\begin{array}{c}\text { MIX } \\
\text { RATIO }\end{array}$ & $\begin{array}{c}\text { Compressive } \\
\text { Strength (CS) } \\
\text { (MPa) }\end{array}$ & $\begin{array}{c}\text { Mass } \\
\text { (g) }\end{array}$ & $\begin{array}{c}\text { Density } \\
\text { (D) } \\
\left(\mathbf{k g} / \mathbf{m}^{\mathbf{3}}\right)\end{array}$ \\
\hline R1 & 20 & 205.04 & 1564.0 \\
\hline R2 & 6 & 228.20 & 1740.7 \\
\hline R3 & 0 & 198.15 & 1511.5 \\
\hline R4 & 14 & 203.25 & 1550.4 \\
\hline R5 & 6 & 227.29 & 1733.8 \\
\hline R6 & 0.4 & 173.60 & 1324.2 \\
\hline R7 & 12 & 205.04 & 1564.0 \\
\hline R8 & 2 & 199.61 & 1522.6 \\
\hline R9 & 0 & 192.71 & 1470.0 \\
\hline R10 & 2 & 206.33 & 1573.9 \\
\hline
\end{tabular}

Based on the statistical analysis of these data, the best fit model for both response is quadratic equation as shown below. For compressive strength (CS) equation (4), linear model terms $\mathrm{A}, \mathrm{B}$, and $\mathrm{C}$, as well as $\mathrm{AB}$ and $\mathrm{AC}$ are all significant terms since their $\mathrm{P}$-values are less than 0.10 , as shown in Table 5. However, model term $\mathrm{BC}$ will not be included since its p-value is 0.1251 . On the other hand, for density (D) equation (5), all model terms are considered significant.

$$
\begin{aligned}
C S= & 20.62 \mathrm{~A}+5.67 \mathrm{~B}+0.40 \mathrm{C}-3.36 \mathrm{AB}-21.91 \mathrm{AC} \\
D= & 1554.78 \mathrm{~A}+1741.36 \mathrm{~B}+1501.98 \mathrm{C}-362.98 \mathrm{AB}+ \\
& 808.66 \mathrm{AC}-1163.38 \mathrm{BC}
\end{aligned}
$$

Table 5. P-values of Model Terms

\begin{tabular}{|c|c|c|}
\hline \multirow{2}{*}{$\begin{array}{c}\text { MODEL } \\
\text { TERMS }\end{array}$} & \multicolumn{2}{|c|}{ P-VALUES } \\
\cline { 2 - 3 } & $\begin{array}{c}\text { CS } \\
\text { (Equation 4) }\end{array}$ & $\begin{array}{c}\text { D } \\
\text { (Equation 5) }\end{array}$ \\
\hline A, B, C & 0.0021 & 0.0558 \\
\hline AB & 0.7389 & 0.0844 \\
\hline AC & 0.0803 & 0.0070 \\
\hline BC & 0.1251 & 0.0019 \\
\hline
\end{tabular}

$* A=C F A, B=C T W, C=S B E$

Moreover, the p-values presented in Table 6 for equation (4) and (5) are less than 0.05 , which means that the regression model is statistically significant. Furthermore, the standard deviation is close to zero, indicating a minimal deviation, and coefficients of determination (R-squared) are very near to 1 , indicating that the data fit the model.
Table 6. ANOVA at 5\% level of significance

\begin{tabular}{|c|c|c|}
\hline MODEL & CS (Equation 4) & D (Equation 5) \\
\hline p-value & 0.0073 & 0.0065 \\
\hline Std. dev. & 2.12 & 35.75 \\
\hline Mean & 6.24 & 155.51 \\
\hline R-squared & 0.9584 & 0.9608 \\
\hline
\end{tabular}

For optimization, the desirability function was used wherein the compressive strength was set to $12 \mathrm{MPa}$, meeting the minimum requirement of $11.7 \mathrm{MPa}$ from ASTM C90-14 for moderately-loaded, lightweight load bearing concrete, while density was minimized, with a maximum value of $1680 \mathrm{~kg} / \mathrm{m}^{3}$ in accordance with PNS ASTM C332:2013, as shown in Table 7.

Table 7. Constraints for Optimization

\begin{tabular}{|c|c|c|c|}
\hline COMPOSITION & GOAL & $\begin{array}{c}\text { LOWER } \\
\text { LIMIT }\end{array}$ & $\begin{array}{c}\text { UPPER } \\
\text { LIMIT }\end{array}$ \\
\hline A (CFA) & is in range & 0 & 500 \\
\hline B (CTW) & is in range & 0 & 500 \\
\hline C (SBE) & is in range & 0 & 500 \\
\hline $\begin{array}{c}\text { Compressive } \\
\text { Strength }\end{array}$ & target $=12$ & 11.7 & 14 \\
\hline Density & Minimize & 0 & 1680 \\
\hline
\end{tabular}

The resulting ternary plots for compressive strength and density are shown in Figure 2. The green-shaded region in the figures indicates the possible mix ratios of the raw materials that would meet the desired properties of the product.

Figure 2(a) and Equation 4 indicates that the increase in the compressive strength of sodium aluminosilicate monolith is due to the CFA. Moreover, SBE and CTW decrease the compressive strength of the product as shown by the downward slope in the response surface plot. The effect of SBE to decrease the strength may be attributed to the remaining residual oil after leaching since oil reacts to sodium hydroxide to form soap through saponification.

On the other hand, all materials contributed linearly to the density of the product as shown in Figure 2(b) and Equation 5, but a higher proportion of SBE and CTW would give a lower density. From this, the optimum mix ratio for the production of sodium aluminosilicate monolith is $55.95 \%$ CFA, $38.73 \%$ CTW and 5.31\% SBE, with a desirability of 0.283 . 


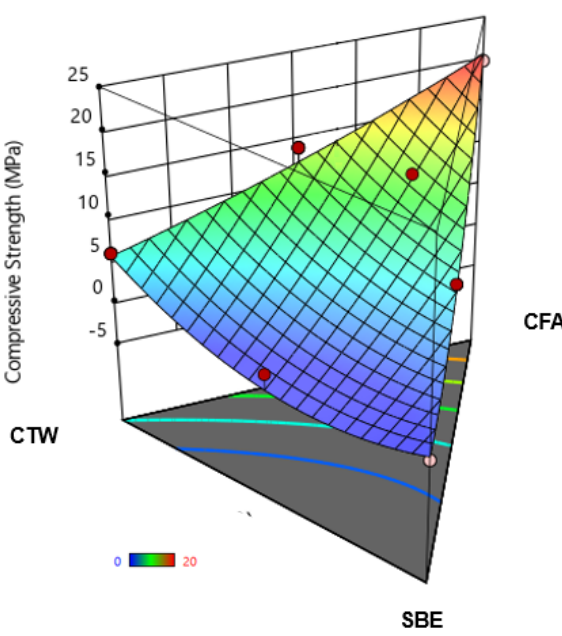

(a)

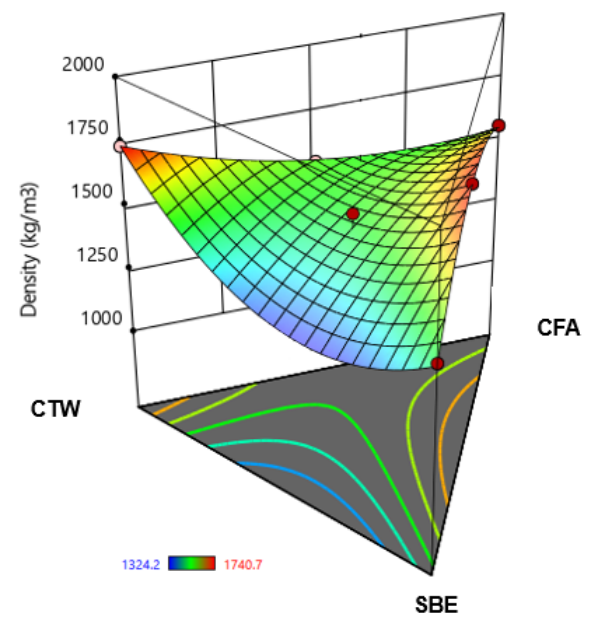

(b)

Figure 2. Response surface plots of a) the compressive strength b) density of sodium aluminosilicate monoliths

\subsection{Methylene blue determination \\ (MB) adsorption}

To determine the adsorption mechanism, the results are fitted into the Langmuir and Freundlich isotherm plots as shown in Figure 3.

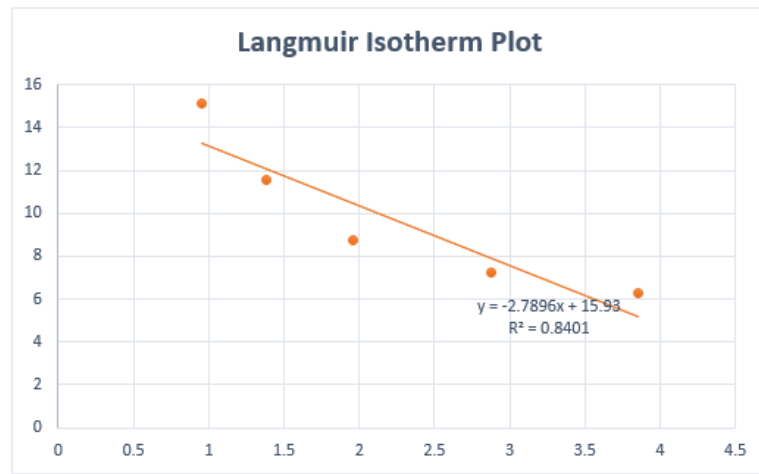

(a)

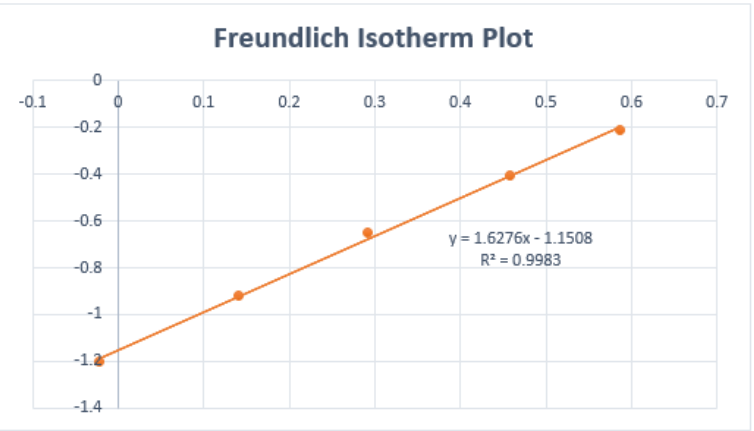

(b)

Figure 3. Adsorption Isotherm Plots of a) Langmuir Model and b) Freundlich Model

The Pearson correlation coefficient of Freundlich isotherm plot is closer to 1 , therefore the adsorption behavior can be fitted to this model. Based on the equation given by the Freundlich isotherm, the adsorption intensity $(1 / \mathrm{n})$ is equal to 1.63 , this means that sodium aluminosilicate monoliths gave a favorable adsorption behavior. On the other hand, the Freundlich constant obtained is 0.07 for sodium aluminosilicate monoliths.

\subsection{Characteristics of produced sodium aluminosilicate monolith}

The produced sodium aluminosilicate monolith was subjected to a quantitative analysis as per ASTM C0109/C0109M: Standard Test Method for Compressive Strength of Hydraulic Cement Mortars and was found to conform to the specifications of ASTM C90-14 for moderately-loaded, lightweight load bearing concrete (minimum compressive strength of $11.7 \mathrm{MPa}$ and maximum density of $1680 \mathrm{~kg} / \mathrm{m}^{3}$ ) by exhibiting the following properties: average compressive strength of $12.4 \mathrm{MPa}$, density of $1310 \mathrm{~kg} / \mathrm{m}^{3}$, and porosity of $17.03 \%$. Furthermore, adsorption capacity was tested through UV-vis spectrophotometer resulting to methylene blue adsorption intensity of $1.63 \%$ and a Freundlinch constant of 0.07 .

\section{Conclusion}

The production of sodium aluminosilicate monolith has been obtained through geopolymerization of coal fly ash (CFA, ceramic tile wastes (CTW) and spent bleaching earth (SBE). In this study, the properties of monolith produced from the ternary mixture of $56-39-5$ by mass ratio of CFA-CTW-SBE and an alkali solution containing $80 \% 8 \mathrm{M} \mathrm{NaOH}$ and $20 \%$ sodium silicate conformed to the specifications set by ASTM C90-14, and ASTM C332. The product obtained compressive strength of $12.4 \mathrm{MPa}$ and $1310 \mathrm{~kg} / \mathrm{m}^{3}$ density. Furthermore, due to the addition of hydrogen peroxide, the product obtained a porosity of $17.03 \%$ and methylene blue adsorption intensity of $1.63 \%$ signifying that the product may be used as an adsorbent for wastewater treatment. 


\section{References}

Aly, S. T., D. M. Kanaan, A. S. El-Dieb, and S. I. AbuEishah; "Properties of Ceramic Waste Powder-Based Geopolymer Concrete," International Congress on Polymers in Concrete, pp. 429-435, Washington D.C., USA (2018)

Arrifin, N., M. Abdullah, Z. Rozainy, and M. Murshed; "Geopolymer as an Adsorbent of Heavy Metals: A Review," The 3rd Electronic and Green Materials International Conference, 020030, Krabi, Thailand (2017)

Department of Energy; 2017 Power Demand and Supply Highlights. Available online: https://www.doe.gov.ph/ default/files/pdf/electric power/ 2017- power- demandand-supply-highlights.pdf?ckattempt $=1$ (2018a)

Department of Energy: Philippines Coal Consumption by Year, Available online: https://www.doe.gov.ph/ energy-statistics? $\mathrm{q}=$ energy-resources/coal-statistics (2018b)

Dimas, D. D., I. P. Giannopoulou, and D. Panias; "Utilization of Alumina Red Mud for Synthesis of Inorganic Polymeric Material,". Mineral Processing \& Extractive Metallurgy Review, 30(3), 211-239 (2009)

Febrianto J., A. N. Kosasih, J. Sunarso, J. Yi-Hsu; "Equilibrium and Kinetic Studies in Adsorption of Heavy Metals Using Biosorbent: A Summary of Recent Studies". Journal of Hazardous Materials, 162, 616645 (2009)

Ho, V. and A. Orbecido; "Investigation on Mixture Design of One-part Geopolymer from Fly Ash and Water Treatment Sludge," The 24th Regional Svmposium on Chemical Engineering (RSCE 2017), 005009, Semarang, Indonesia (2018)

Huang, Y. and J. Chang; "Biodiesel Production from Residual Oils Recovered from Spent Bleaching Earth," Renewable Energy, 35(1), 269-274 (2010)

Kalaw, M. E. L., A. B. Culaba, H. T. Nguyen, K. Nguyen, H. Hinode, W. Kurniawan, and M. A. Promentilla: "Mechanical and Thermal Properties of Geopolymers from Mixtures of Coal Ash and Rice Hull Ash Using Water Glass Solution as Activator," ASEAN Journal of Chemical Engineering, 2, 51-61 (2018)

Kim, W. H., J. Park, J. Cho, T. Y. Jeong, and P. K. Park; "Application of Langmuir and Freundlich Isotherms to Predict Adsorbate Removal Efficiency or Required Amount of Adsorbent," Journal of Industrial and Engineering Chemistry, 28, 241-246 (2015)

Lee, C. K., K. S. Low, and L. C. Chung; "Removal of Some Organic Dyes by Hexane - extracted Spent Bleaching Earth,"Journal of Chemical Technology \& Biotechnology: International Research in Process, Environmental and Clean Technology, 69(1), 93-99 (1997)

Malenab, R., J. Ngo, and M. A. Promentilla; “Chemical Treatment of Waste Abaca for Natural Fiber-reinforced Geopolymer Composite," Materials, 10(6), 579 (2017)

Mas, M. A., L. Reig Cerdá, J. Monzó, M. V. Borrachero, and J. Payá; "Ceramic Tiles Waste as Replacement Material in Portland Cement," Advances in Cement Research, 28(4), 221-232 (2015)

Nguven, H. T., T. K. Pham, and M. A. Promentilla: "Development of Geopolymer-based Materials from Coal Bottom Ash and Rice Husk Ash with Sodium
Silicate Solutions," Congrès International de Géotechnique-Ouvrages-Structures, 4, 402-410, Ho Chi Minh City, Vietnam (2017)

Novais, R. M.. G. Ascensão, D. M. Tobaldi, M. P. Seabra, and J. A. Labrincha; "Biomass Fly Ash Geopolymer Monoliths for Effective Methylene Blue Removal from Wastewaters," Journal of Cleaner Production, 171, 783-794 (2018)

Oladosu, W. A., Z. A. Manan, and S. W. Alwi; "Recovery of Vegetable Oil from Spent Bleaching Earth: State-of-the-Art-and-Prospect-for-Process-

Intensification," Chemical Engineering Transactions, $\mathbf{5 6}$ 133-138 (2017)

Organisation for Economic Co-operation and Development and Food and Agriculture Organization; OECD-FAO Agricultural Outlook 2017-2026, pp. 2135, OECD Publishing, Paris, France (2017)

Palmero, P., A. Formia, P. Antonaci, S. Brini, and J. Tulliani; "Geopolymer Technology for ApplicationOriented Dense and Lightened Materials. Elaboration and Characterization," Ceramics International, $\mathbf{4 1}$, 12967-12979 (2015)

PNS ASTM C332:2013 Standard Specification for Lightweight Aggregates for Insulating Concrete, Philippine National Standards, ASTM International, West Conshohocken, USA (2009)

Provis, J. L. and S. A. Bernal; "Geopolymers and Related Alkali-Activated Materials," Annual Review of Materials Research, 44, 299-327 (2014)

Provis, J. L. and J. S. J. van Deventer; Alkali Activated Materials: State-of-the-Art Report, RILEM TC 224AAM (2014)

Reig, L., M. M. Tashima, L. Soriano, M. Borrachero, J. Monzó and J. Payá; "Alkaline Activation of Ceramic Waste Materials," Waste and Biomass Valorization, 4(4), 729-736 (2013)

Saniayan, J. G., A. Nazari, L. Chen, and G. H. Nguven; "Physical and Mechanical Properties of Lightweight Aerated Geopolymer," Construction and Building Materials, 79, 236-244 (2015)

Sumabat, A. K. R. A. J. Mañalac, N. T. Nguven. M. E. Kalaw, R. R. Tan, and M. A. Promentilla; "Optimizing Geopolymer-Based Material for Industrial Application with Analytic Hierarchy Process and Multi-Response Surface Analysis," Chemical Engineering Transactions, 45, 1147-1152 (2015)

Tigue, A. A. S., J. R. Dungca, H. Hinode, W. Kurniawan, and M. A. Promentilla; "Synthesis of a One-part Geopolymer System for Soil Stabilizer Using Fly Ash and Volcanic Ash," The 24th Regional Symposium on Chemical Engineering (RSCE 2017), 05017, Semarang, Indonesia (2018)

Timakul, P., K. Thanaphatwetphisit, and P. Aungkavattana; "Effect of Silica to Alumina Ratio on the Compressive Strength of Class C Fly Ash-Based Geopolymers," Key Engineering Materials, 659, 80-84 (2015)

Wangrakdiskul, U., P. Khonkaew, and T. Wongchareonsin; "Use of the Spent Bleaching Earth from Palm Oil Industry in Non Fired Wall Tiles," International Journal of Advanced Culture Technology, 3(2), 15-24 (2015) 